\title{
NOTE
}

\section{Praziquantel (Droncit) is effective against diplostomosis of grasscarp Ctenopharyngodon idella and silver carp Hypophthalmichthys molitrix}

\author{
Csaba Székely, Kálmán Molnár \\ Veterinary Medical Research Institute, Hungarian Academy of Sciences, H-1581 Budapest, PO Box 18, Hungary
}

\begin{abstract}
In laboratory experiments praziquantel (Droncit) effectively destroyed metacercariae of Diplostomum spathaceum (s. l.) parasitizing the eye lens of grasscarp Ctenopharyngodon idella and silver carp Hypophthalmichthys molitrix. A single treatment with Droncit fed at a dose of 330 $\mathrm{mg} \mathrm{kg}{ }^{-1}$ body mass showed $100 \%$ efficacy against metacercariae parasitizing grasscarp. A similar, complete parasiticidal efficacy was achieved when infected grasscarp and silver carp specimens were exposed to a solution containing $1 \mathrm{mg}$ praziquantel $1^{-1}$ for at least $90 \mathrm{~h}$. Using shorter exposures $(20 \mathrm{~min}$ to $1 \mathrm{~h}$ ) but elevated praziquantel doses (10 to $\left.100 \mathrm{mg} \mathrm{l}^{-1}\right)$, some parasites survived but even here the intensity effect reached 67 to $97 \%$
\end{abstract}

Diplostomosis, which is one of the commonest fish diseases, causes substantial losses in cultures both of trout (Bylund \& Sumari 1981) and of common carp, silver carp and grasscarp (Bauer et al. 1981). It is caused by the cercariae and metacercariae of Diplostomum spathaceum (s. l.), which migrate in the body of fish and colonise the eye lens (Molnár 1974).

So far only few researchers have dealt with the problem of medication of Diplostomum spathaceum infection. Ramadan (1973) tested 26 chemical compounds, 7 of which proved effective in vitro but not in vivo when used in a medicated diet. Praziquantel (Droncit) proved to be the first effective drug in vivo against Diplostomum metacercariae. Bylund \& Sumari (1981) were the first to report on its efficacy, testing against diplostomosis of rainbow trout Salmo gairdneri. They mixed praziquantel with the feed at a very high dose $(330 \mathrm{mg}$ $\mathrm{kg}^{-1}$ body mass) and fed it for $1 \mathrm{wk}$ or for 1 mo at $4 \mathrm{~d}$ intervals. Treatment resulted in damage to and death of metacercariae.

Moser \& Sakanari (1986) tested the efficacy of prazi- quantel against Diplostomum spathaceum cercariae developing in snails (Physa and Lymnaea spp.), using baths containing $5.68 \mathrm{mg}$ praziquantel $\mathrm{ml}^{-1}$. Exposures of 12,24 and $48 \mathrm{~h}$ resulted in degeneration and destruction of the cercariae. Heckmann (1987) used praziquantel against $D$. spathaceum metacercariae parasitizing the lens of Cottus bairdi, and found it effective both by the intramuscular and intraperitoneal route and as a bath. Zhatkanbayeva \& Heckmann (1990) reported on the efficacy of praziquantel, used as baths of different concentrations, against Diplostomum pusilIum and Apatemon gracilis, 2 trematode parasites of Nemacheilus dorsalis.

The efficacy testing of praziquantel, applied as medicated diet or as a bath, against diplostomosis of herbivorous fishes (grasscarp, silver carp) is reported in this paper for the first time.

Materials and methods. Age-group 1+ grasscarp (average body mass: $16 \mathrm{~g}, \mathrm{SD}: 3.4$ ) and silver carp fry (average body mass: $13 \mathrm{~g}, \mathrm{SD}: 4.6$ ), obtained from a farm pond, were used. The fish showed $100 \%$ prevalence of infection by Diplostomum spathaceum metacercariae in the eye lens. The mean intensity of infection in grasscarp and silver carp was 85 (SD: 19.5) and 125 (SD: 14.4) metacercariae, respectively. The experimental fish were kept in $50 \mathrm{l}$ aerated aquaria at 20 to $23^{\circ} \mathrm{C}$ water temperature. During diet experiments the water was changed 2 to 3 times per week. The experiments were carried out between 8 May and 20 September 1990.

The first series of experiments consisted of 4 efficacy tests of praziquantel added to the diet of grasscarp. Droncit $\left.{ }^{(}\right)$a drug containing the isoquinoline pyrazine 
derivative praziquantel as active compound, was used for preparing the medicated diet. Droncit tablets (each containing $50 \mathrm{mg}$ active ingredient) were ground to powder and mixed into the pulverized diet. For each feeding a fresh pellet was prepared from the dry mix by adding a small volume of water. The medicated diet was fed at a dose of 35 to $330 \mathrm{mg} \mathrm{kg}^{-1}$ body mass $\mathrm{d}^{-1}$ for different times in the treated groups. The fish were fed by hand and all consumed the feed immediately and uniformly. The experimental groups comprised 3 to 20 individuals (Table 1 ).

The second series of experiments consisted of 3 efficacy tests in grasscarp and silver carp, using the test compound in a bath. Praziquantel was dissolved in $2 \mathrm{ml}$ ethanol and added to tap water. The treated groups comprised 3 to 12 individuals. Exposure time ranged between $20 \mathrm{~min}$ and $168 \mathrm{~h}$ and drug concentration of the bathing solution was between 0.05 and $100 \mathrm{mg} \mathrm{l}^{-1}$ (Table 2). After treatment the fish were returned to tap water.

Treated fish were killed at different times ( $1 \mathrm{~h}, 4,5$, 10 , or $15 \mathrm{~d}$ ) after treatment and their eye lenses removed. The lens was first examined by stereomicroscopy for viability of metacercariae, then carefully squashed under a coverslip. Live as well as dead worms were counted in a light microscope.
Results. A single feeding of the medicated diet containing $330 \mathrm{mg}$ praziquantel $\mathrm{kg}^{-1}$ body mass was sufficient to achieve $100 \%$ efficacy (Table 1). Only dead metacercariae were found in the lens. Using doses of 35, 50 or $100 \mathrm{mg}$ praziquantel $\mathrm{kg}^{-1}$ body mass, no complete parasiticidal effect could be achieved even after 3 feedings and in the majority of the fish some metacercariae survived the treatment. However, the intensity effect (IE) of treatment (number of dead parasites after treatment/total number of parasites $\times 100$ ) reached $93.8,88.0$ and $97.5 \%$ respectively even in these cases (Table 1),

When grasscarp and silver carp were bathed in praziquantel solutions of $1 \mathrm{mg} \mathrm{l}^{-1}$ and $10 \mathrm{mg} \mathrm{l}^{-1}$ concentration for $24 \mathrm{~h}$ and $1 \mathrm{~h}$, respectively, IE values between 68.6 and $934 \%$ were obtained. The treatment, however, did not reduce the prevalence of infection (Table 2).

An exposure time of $20 \mathrm{~min}$ to solutions of $50 \mathrm{mg} \mathrm{I}^{-1}$ and $100 \mathrm{mg} \mathrm{l}^{-1}$ concentration showed 66.7 to $96.8 \%$ efficacy. Solutions of such high praziquantel concentration were, however, poorly tolerated: the fish turned upside down, showed reduced respiration and motility, and resumed normal behaviour only after transferral to tap water after treatment.

An exposure time of $90 \mathrm{~h}$ to baths of 0.5 and $1 \mathrm{mg} \mathrm{l}^{-1}$

Table 1. Efficacy of praziquantel given in medicated diet against Diplostomum spathaceum metacercariae parasitizing the eye lens of grasscarp fry

\begin{tabular}{|c|c|c|c|c|c|c|c|}
\hline $\begin{array}{l}\text { Expt } \\
\text { no. }\end{array}$ & $\begin{array}{l}\text { No. of } \\
\text { fish }\end{array}$ & $\begin{array}{l}\text { Duration of } \\
\text { treatment }\end{array}$ & $\begin{array}{l}\text { Dose in diet } \\
\text { (mg kg } \\
\text { body mass) }\end{array}$ & $\begin{array}{c}\text { Prevalence of } \\
\text { infection after } \\
\text { treatment }\end{array}$ & $\begin{array}{l}\text { Mortality } \\
\text { during } \\
\text { treatment }\end{array}$ & $\begin{array}{c}\text { Average no. } \\
\text { of larvae } \\
\text { per fish }\end{array}$ & $\begin{array}{c}\text { Efficacy against } \\
\text { intensity of } \\
\text { infection } \\
(\%) / \mathrm{SD}\end{array}$ \\
\hline \multirow[t]{3}{*}{ I } & 20 & $8 \mathrm{~d}$ (daily) & 330 & $0 / 17$ & 3 & 87.6 & $100.0 / 0.0$ \\
\hline & 20 & $\begin{array}{l}1 \text { mo (at } 4 \text { d } \\
\text { intervals) }\end{array}$ & 330 & $0 / 8^{a}$ & 2 & 135.3 & $100.0 / 0.0$ \\
\hline & 20 & Control & 0 & $17 / 17$ & 3 & 107.8 & $-1-$ \\
\hline \multirow[t]{4}{*}{ II } & 11 & $5 \mathrm{~d}$ (daily) & 330 & $0 / 10$ & 1 & 55.5 & $100.0 / 0.0$ \\
\hline & 10 & $\begin{array}{l}\text { Twice (on Days } \\
1 \text { and } 3 \text { ) }\end{array}$ & 330 & $0 / 10$ & 0 & 72.0 & $100.0 / 0.0$ \\
\hline & 15 & $\begin{array}{l}4 \text { times (on Days } \\
1,4,8 \text { and } 12 \text { ) }\end{array}$ & 330 & $0 / 10^{b}$ & 0 & 87.4 & $100.0 / 0.0$ \\
\hline & 5 & Control & 0 & $5 / 5$ & 0 & 79.4 & $-1-$ \\
\hline \multirow[t]{3}{*}{ III } & 12 & Once & 330 & $0 / 12$ & 0 & 55.6 & $100.0 / 0.0$ \\
\hline & 12 & $\begin{array}{l}3 \text { times (on Days } \\
1,2 \text { and } 5 \text { ) }\end{array}$ & 35 & $6 / 12$ & 0 & 68.2 & $93.8 / 2.8$ \\
\hline & 7 & Control & 0 & $7 / 7$ & 0 & 58.0 & $-1-$ \\
\hline \multirow[t]{3}{*}{ IV } & 5 & $\begin{array}{l}3 \text { times (on Days } \\
1,2 \text { and } 3 \text { ) }\end{array}$ & 100 & $4 / 5$ & 0 & 80.6 & $97.5 / 2.5$ \\
\hline & 6 & $\begin{array}{l}3 \text { times (on Days } \\
1,2 \text { and } 3 \text { ) }\end{array}$ & 50 & $6 / 6$ & 0 & 72.0 & $88.0 / 8.2$ \\
\hline & 3 & Control & 0 & $3 / 3$ & 0 & 53.0 & $-1-$ \\
\hline
\end{tabular}


containing $1 \mathrm{mg}$ praziquantel $1^{-1}$ proved to be the best as it gave $100 \%$ efficacy. With shorter exposures complete parasiticidal activity could not be achieved but the intensity of infection was markedly reduced. For this a $1 \mathrm{~h}$ exposure to a solution of $10 \mathrm{mg}^{-1}$ praziquantel concentration seems to be the most suitable. This gives 93 to $94 \%$ efficacy; however, some surviving, in many cases degenerated, metacercariae remain in all fish specimens treated. Exposures to high (50 or $100 \mathrm{mg} \mathrm{l}^{-1}$ ) concentrations of praziquantel are expensive and poorly tolerated by fish. As praziquantel treatment is very costly, we tested baths of very low praziquantel concentration $(0.1$ and $0.05 \%)$; however, these were ineffective even after an exposure time of $168 \mathrm{~h}$ ( $1 \mathrm{wk}$ ).

Although the high price of praziquantel often prevents its use even in human medicine, its use in valuable stocks (spawners, exhibition specimens) is practicable. A 90 to $168 \mathrm{~h}$ exposure to baths of $1 \mathrm{mg} \mathrm{l}^{-1}$ praziquantel or a single feeding of medicated diets containing $330 \mathrm{mg}$ praziquantel $\mathrm{kg}^{-1}$ body mass are the recommended routes of application.

As Diplostomum spathaceum cercariae continuously infect fish kept in ponds, valuable fish treated with

Responsible Subject Editor: W. Körting, Hannover, Germany praziquantel should be transferred to an environment where reinfection cannot occur.

\section{LITERATURE CITED}

Bauer, O. N., Musselius, V. A., Strelkov, J. A. (1981). Diseases of pond fishes. Legkhaya i pistsevaya promishlennost. Moscow (in Russian)

Bylund, G., Sumari, O. (1981). Laboratory tests with Droncit against diplostomiasis in rainbow trout, Salmo gairdneri Richardson. J. Fish Dis. 1. 259-264

Heckmann, R. A. (1987). The efficacy of praziquantel and ivermectin against selected helminths of fishes. Abstracts of papers read at the 2 nd Int. Symp. of Ichthyoparasitol., 27 Sept.-3 Oct. 1987, Tihany, Hungary, p. 25

Molnár, K. (1974). On diplostomosis of the grasscarp fry. Acta Vet. Acad. Sci. Hung. 24: 63-71

Moser, M., Sakanari, J. (1986). The effects of praziquantel in various larval and adult parasites from freshwater and marine snaiis and fish. $j$. Parasitol. $72: 175-i 76$

Ramadan, H. H. (1973). Untersuchungen zur systematischen Therapie von Diplostomum-Invasionen bei Regenbogenforellen (Salmo gairdneri). Dissertation der Biowissenschaftlichen Fakultät der Humboldt-Univ., Berlin

Zhatkanbayeva, D., Heckmann, R. A. (1990). Effectiveness of praziquantel against trematodoses of fish. Book of Abstracts, VIIth Int. Congr. of Parasitol., 20-24 August 1990, Paris, p. 869

Manuscript first received: January 29, 1991

Revised version accepted: May 22, 1991 